\title{
The Philippines-China Asymmetric Relations and Possible Scenarios in The South China Sea
}

\author{
Bruno Hendler \\ Ph.D Candidate on International Political Economy at Federal University of Rio de Janeiro, Brazil \\ Corresponding author: bruno_hendler@hotmail.com
}

\begin{abstract}
This paper proposes a scenario for solving the stalemate between China and the Philippines in the South China Sea using Brantly Womack's Theory of Asymmetry. The central hypothesis is that, given the asymmetry of material (economic and geopolitical) capabilities between the two countries, it is possible to find an intermediary path of negotiation through mutual concessions, so that the final outcome serves the interests of both parties.
\end{abstract}

Keywords-theory of asymmetry, south china sea, chinaphilippines relations

\section{INTRODUCTION}

This paper proposes a scenario for solving the stalemate between China and the Philippines in the South China Sea using Brantly Womack's Theory of Asymmetry [1]. The central hypothesis is that, given the asymmetry of material (economic and geopolitical) capabilities between the two countries, it is possible to find an intermediary path of negotiation through mutual concessions, so that the final outcome serves the interests of both parties. The article is divided in three parts, besides this introduction: a) a theoretical discussion on the Theory of Asymmetry; b) a theoretical framework proposal based on the patterns of asymmetric interaction between China and the Philippines; and c) possible scenarios for solving the stalemate in the South China Sea using the proposed framework and the Asymmetry Theory.

\section{THE THEORY OF ASYMMETRY}

The theoretical framework of this article is Brantly Womack's Theory of Asymmetry. Womack studies ChinaVietnam historical relations by the countries' "basic parameters of international insertion", defined as "basic realities of a country's situation that help determine how it views relations with other countries" [1]. And even as the author admits that these parameters can change, they change at a slow pace. The asymmetry between the stronger state $(\mathrm{A})$ and the weaker state (b) is a given, derives from the differences between the basic parameters and refers to demography, territory, internal political structures, social cohesion, access to resources, etc. Thus, since the parameters of China and Vietnam are maintained, the latter will remain in position (b) and the former will remain in position (A).
The T.A. presents some basic premises. First, an asymmetrical relationship does not mean absolute control of (A) over (b): on the contrary, it only occurs when the stronger side is unable to totally subdue/defeat the weaker. In face of a stalemate or the simple impossibility of annexation, both are pushed into a "normal" and negotiated relationship of asymmetry.

Second, most asymmetric relations display a pattern of stability, and an open conflict is the exception. Thus, T.A.'s object of study is precisely the handling of asymmetric bilateral relations and how these can bring costs or benefits to both sides.

Third, an asymmetric relation is made up of two distinct sub-relations: (A) => (b) and (b) => (A) $(2004,78)$ defined by different degrees of vulnerability. Since the basic parameters of the agents are different, their mutual goals and expectations can be convergent even in asymmetry. Still, the general rule is that (b) tends to be more sensitive and vulnerable to (A) than vice versa. In this, Womack borrows from Nye the concept of vulnerability as the ability of a state to respond to external stimuli, whether as threats or opportunities.

From these premises, we summarize the key points of T.A. Regarding the expectation of objectives, (A) expects deference and submission of (b), that is, meaning that the asymmetric relation will not be threatened by political-military actions such as balance of power and military threat, or in the economic sphere with competition in strategic sectors. On the other hand, (b) expects its autonomy, interests and expectations to be recognized and respected, both in terms of security and economic development. And it is precisely the field of dispute between the deference to (A) and the autonomy of (b), expressed in material and symbolic actions, that can lead to a stable asymmetry or to conflict, which brings us to the next point.

Differences of mutual attention. Given the asymmetry of basic parameters, (A) devotes less attention to (b) than vice versa and its foreign policy formulation tends to be more responsive and less coordinated to (b) because it has a higher number of external concerns [1]. On the other hand, (b) presents a more proactive and coordinated foreign policy toward (A) because it is more sensitive and vulnerable to its actions. Thus, both threats and benefits tend to be more relevant to (b) than to (A). 


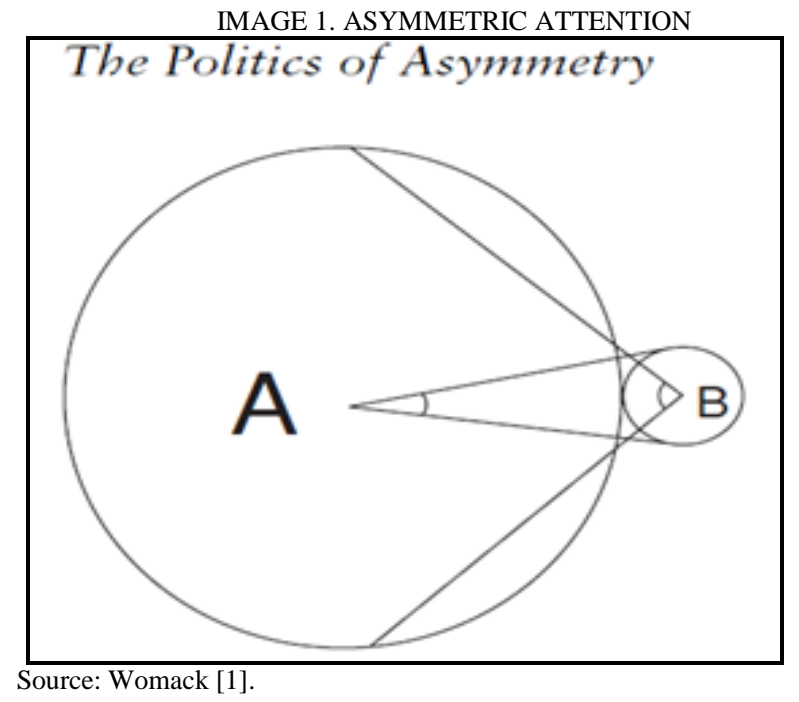

Misperceptions. The difference in mutual attention leads to two ideal types of vicious cycles: bullying and paranoia. The stronger side embodies the figure of the bully, using its power and wealth to maintain the hierarchy and deference of the weaker, which adopts a posture of paranoia, feeling surrounded by the actions of the stronger and seeing its autonomy threatened [1].

Conflict, stalemate and normalization. Bearing in mind the historic China-Vietnam relationship, Womack suggests that conflicts derive from the vicious cycle of bullying and paranoia and acquire traits of "heroic resistance" to (b) and "punitive mission" to (A). Examples such as China's invasion of Vietnam during Yuan and Ming dynasties in the 14th and 15th centuries, and the clashes between the People's Republic of China and the Socialist Republic of Vietnam in 1979 reinforce this thesis.

The stalemate is reached when both sides perceive that there is no more possibility of victory (unilateral resolution of the conflict) in the short term. The frustration resulting from this dead end pushes both to a negotiated, albeit asymmetric, resolution. (A) is frustrated by not being able to impose its will despite its strength - and has its reputation, self-image and credibility stained. And (b), which suffers more with the material costs of the conflict (at least in relative terms), tends to promptly accept negotiation and make more concessions.

Peace agreements tend to re-establish the basis of the deference-autonomy dichotomy through the normalization process. The post-conflict window of negotiations can be analyzed by Robert Putnam's "two-level game", which proposes a tool to examine the fitting between domestic interests and interstate negotiations [2]. In sum, the author suggests a "win-set of negotiation in which both states must make concessions that are acceptable to their internal publics in order to find a middle ground. Naturally, bargaining power shall vary according to the end-of-conflict conjuncture, but the asymmetry of the basic parameters of (A) and (b) will remain as a key factor.

Once the conflict is over, relations tend to move from normalization to normality, which means the gradual construction of channels of contact such as inclusive rhetoric, routinization of processes, creation of joint technical commissions, diplomatic rituals, and dialogue in multilateral forums [2]. These processes should create a neutral zone that reduces mistrust and mutual resentment, turning the use of force unlikely and, ultimately, halting the vicious cycle of bullying-paranoia.

\section{PATTERNS OF INTERACTION IN ASYMMETRIC RELATIONS}

In this article we propose a theoretical model to search for the causal links between elements of political economy and security from the perspective of the Asymmetry Theory. The vertical axis is linked to the gains or costs in the field of hard politics, that is, the dynamics of political and military power among states. The horizontal axis refers to the gains or costs in the field of political economy, that is, to the dynamics of wealth generation and insertion in the global value chains.

The initial position of a state is defined by its basic parameters of external posture and its interaction with the other state. The higher it is in the upper quadrants, the greater the political-strategic gain of a state towards the other and to itself. And the closer to the right quadrants, the greater the economic gains also in absolute and relative terms. Conversely, the more to the left, the greater the economic costs and the more to the lower quadrants, the higher the political costs.

Take the case of territorial disputes in the South China Sea (SCS). With regard to the economic axis, The Philippines is farther to the right because the economic activities in the SCS, especially fishing, but also the expectation of exploitation of energy resources, occupy (or may occupy, in the case of energy) a higher portion of the country's GDP than China's. Thus the great distance between the Philippines and China on the horizontal axis derives from the immense asymmetry of the basic economic parameters and the higher relative importance of fishing and the exploitation of energy resources for The Philippines. That is, although these activities may have positive impacts on Southern China's provinces, The Philippines' economy may benefit much more, in relative terms, with the economic access to the SCS.

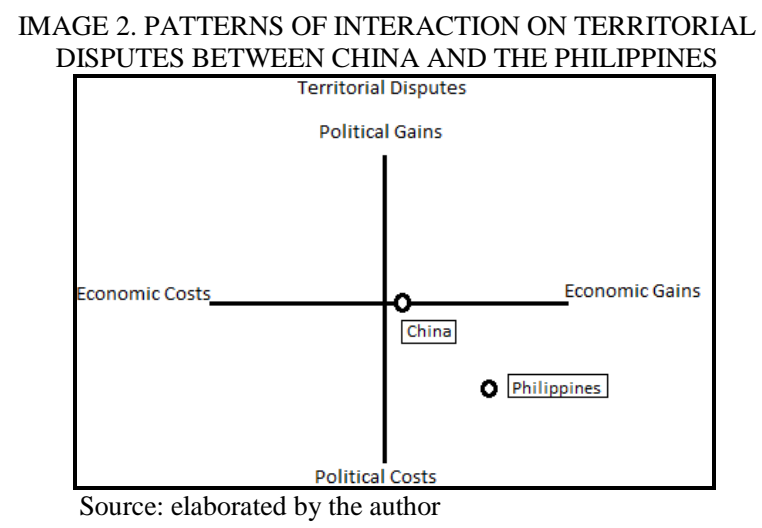

For China, the economic relevance of the SCS is blended with the logic of security: the region is more important for its trade routes than by the natural resources it harbors. Thus, China is in the middle of the political axis for some reasons. On 
the one hand, China's SCS control represents strategic gains in access to blue waters, protection of maritime routes and military outreach in the region. On the other hand, the construction of artificial islands and the non-observance of both, the Permanent Court of Arbitration's decision and the principle of free navigation of the seas, jeopardizes China's soft power effort of joining regional security institutions and strengthening bilateral diplomatic ties, including with The Philippines, which may call for new US and Japanese military support. Thus, China's initial position on the political front is intermediate, as the costs and benefits tend to be balanced.

The Philippines has more to lose than to win in the politicomilitary arena. The country's strategic thinking is constrained by variables of internal threats (guerrillas and drug trafficking), external threats (such as China's maritime bullying), and the historical reliance on US cooperation/protection, resulting in a defensive strategic mindset. Thus, conditions as the lowmiddle-income country status, the lack of efficiency in resolving internal threats, the reliance on sea lanes and the simple asymmetry of military force vis-à-vis China makes The Philippines an actor with much more to lose strategically in SCS territorial disputes, no matter how many international tribunals vote in its favor.

\section{THE PHILIPPINES-CHINA ASYMMETRIC RELATIONS AND Possible SCENARIOS FOR SETTLING THE LitigATION IN THE SOUTH CHINA SEA}

The conditions and possibilities form a win-set table of negotiation [2]. In economic terms, the maximum gain for both sides is the monopoly of exploitation of the resources in the SCS. China would still have an advantage, as natural gas and oil can be exploited by Chinese companies, while The Philippines would need to attract foreign companies despite the high risk of conflict. With regards to fishing both countries are autonomous, but this activity is proportionally more relevant to the Philippine economy. The ideal resolution to the impasse would be joint exploration by China and the Philippines, a process that has even occurred during the Arroyo government in 2004 and also included Vietnam, but was discontinued a few years later due to mutual distrust.

In the strategic dimension, the asymmetry in the basic parameters creates different expectations of resolution. China's basic parameters involve a historical narrative of the centrality of its tribute system in Southeast Asia; a conception of the southern borders (land and sea) as expansive and mobile (unlike the rather defensive and static borders in the north and west); an idea of Western siege by the US system of hubs and spocks; and, above all, a material force used by a strong and organized state to project power over a region that does not host any major powers or countries with nuclear capability.

The Philippines is an archipelago with a long colonial past, strong social inequality, two major domestic threats (drug trafficking and guerrillas) and armed forces that, despite Duterte's current turn, still rely on cooperation with the US. If, on one hand, this special relation grants some domestic stability and security against internal and external threats, on the other, it restricts the geopolitical ambitions of The
Philippines and keeps the country as one among many pawns of the American strategy on the Asian geopolitical theater.

Thus, the expectations of negotiation on the geopolitical board between the two parties are distinct. The optimal outcome for China is the absolute control of the SCS (according to the "9 dash line") and the monopoly of resource exploitation. The possible concession, signaled on some occasions with different litigating countries, is the joint exploitation of resources without giving up de facto politicalmilitary control, expressed by the occupation of most of the islands and also by the transformation of islets and sandbars into real islands. In addition, China would have to recognize the possession, de facto, of some islands, islets and sandbanks by other countries, and give up bullying against foreign fishing boats. Finally, the worst scenario for China in dealing with the Philippines is the shared political-military control of Scarborough's reefs and islets in an arrangement where US and Japanese forces, under international law, would protect and strengthen the safety of Philippine forces.

As for the Philippines, the optimum result would be the military control of its exclusive economic zone (EEZ) of 200 nautical miles, including the reefs and islets of Scarborough which are mostly under Chinese domain. Since such absolute control is impracticable, the possible concession is to accept China's de facto jurisdiction in exchange for the joint exploitation of the SCS resources and the maintenance of Philippine forces in the few islets under their control. In this sense, the joint exploration would consist of: a) permission of access of the Philippine fishing boats to the region; and b) some kind of royalties share for the exploitation of oil and natural gas reserves. Finally, the worst scenario for the Philippines would be the lack of political-military control of its EEZ, the Chinese veto to fishing activities and the exclusion of exploitation of energy resources.

IMAGE 3. POSSIBLE SCENARIO OF RESOLUTION ON SOUTH CHINA SEA BETWEEN CHINA AND THE PHILIPPINES

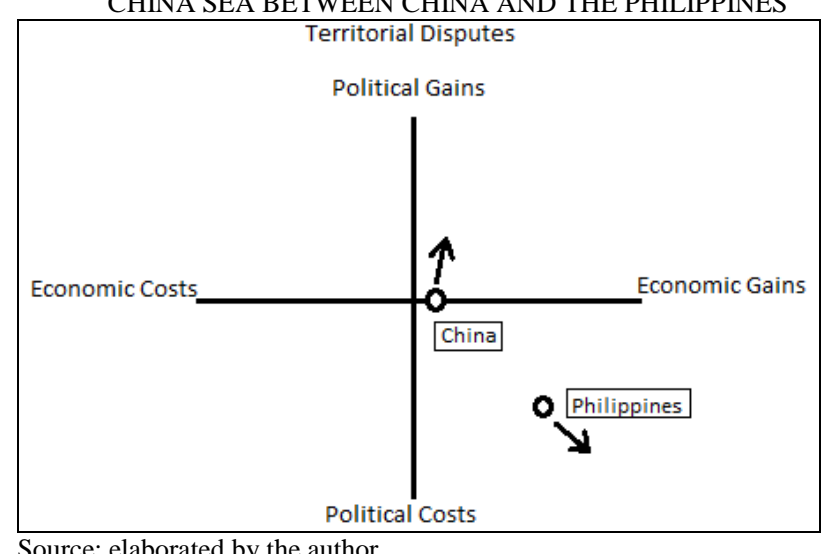

Source: elaborated by the author

The scheme above presents what would be the "acceptable" result for both sides. By making concessions such as allowing the Philippines to practice fishing and permitting a de facto possession of small fractions of Scarborough, such as the Kalayaan Islands, China would obtain far greater political gains. First, as a stronger state (A), it would give a signal of respect for the autonomy of the weaker state (b) and avoid the 
signs of bullying, interpreted as aggression by the weaker side. Second, it would reduce the sense of threat from other litigating countries, which would tend to follow the behavior of The Philippines and tacitly accept a Chinese preponderance. And third, it would deflate the justification for the US presence as a way to guarantee the stability of the region. On the other hand, the economic gains, at least in the short term, would be low because fishing is less important to the Chinese economy and the oil and gas exploitation wound demand a high initial investment and a possible sharing of royalties with The Philippines.

For The Philippines, the "acceptable" result would mean economic gains and political setbacks. The economic gains would be due to the possibility of maintaining the fishing activity and a share in the oil and gas royalties. The political costs would be the loss of access to its 200-mile exclusive economy zone, despite the possession of a few islands it already holds, and also the tacit, almost inevitable recognition of Chinese supremacy in the region, being forced to gradually limit cooperation and military exercises with the Americans and Japanese under the risk of threatening its economic gains.

\section{CONCLUSION}

There are some obstacles to reach the middle ground and avoid the misunderstandings that lead to conflict. On the
Chinese side, they are: a) that Chinese companies accept contracts that transfer royalty shares of oil and natural gas to the Philippines, even if the initial investment is made only by the Chinese; and b) that the Chinese navy grant autonomy to the Philippines at least in respect of fishing activities, avoid typical bullying attitudes of (A) over (b) and accept that Filipino fishermen pose no threat to their de facto sovereignty in Scarborough; and c) that Filipino ownership of islands such as Kalayaan is informally recognized. On the Philippine side, the challenges are: a) to pay the typical deference from (b) to (A) and recognize China's de facto sovereignty by reducing military cooperation with the Americans and the Japanese and prevent it to be seen as a threat to China; and b) that the possible exploitation of energy resources by Chinese companies also includes Filipino interests with the share of royalties.

\section{REFERENCES}

[1] B. Womack, Asymmetry Theory and China's Concept of Multipolarity. Journal of Contemporary China, 13(39), May, pp. 351-366, 2004.

[2] R. Putnam, Diplomacy and domestic politics: the logis of two-level games. International Organization, 42, 3, 1988 